\title{
LA REFORMA DE PROGRAMAS ESCOLARES DE 1936 EN ARGENTINA: PRENSA PEDAGÓGICA Y ESCUELA NUEVA
}

\section{A REFORMA NOS PROGRAMAS ESCOLARES DE 1936 NA ARGENTINA: IMPRENSA PEDAGÓGICA E ESCOLA NOVA}

\section{ELEMENTARY SCHOOL CURRICULUM REFORM IN ARGENTINA IN 1936: PEDAGOGICAL PRESS AND NEW SCHOOL}

\begin{abstract}
Resumo: Neste escrito se analisa na revista La Obra a reforma nos programas escolares do nível inicial em Argentina no ano 1936, como forma de conhecer as discussões no campo pedagógico e com as ideias da Escola Nova. La Obra começou sua publicação em 1921 convertendo-se no dispositivo de difusão de uma parte do movimento escolanovista, fato que possibilitou a conformação de um espaço de sociabilidade pedagógica a partir da qual sustentam posiciones próprias, que inclusive eram opostas em alguns casos as propostas oficiais. $\mathrm{O}$ argumento principal é que este grupo escolanovista, ao incrementar seu poder e influencia, motorizou o processo de reforma que conclui em 1936 com a legislação de novos programas que substituem os anteriores do ano 1910.
\end{abstract}

Palavras-chave: Escola Nova. Campo pedagógico. Prensa pedagógica. Reforma de programas.

\begin{abstract}
Taking as a starting point the magazine La Obra, the Elementary school curriculum reform in Argentina in 1936 is analysed with the aim of learning the debates in the pedagogical field and the role played by the New School ideas. La Obra was first published in 1921 and it became the means of spreading part of the progressive movement. That was a fact that made possible the creation of a pedagogical sociability space from which new positions were taken - in some cases, opposed to the official education politics. The main argument is that this progressive group, having increased its power and its influences, encouraged the reform process, which concluded in 1936 when the new curriculum was passed to replace the previous one from 1910.
\end{abstract}

Keywords: New School. Pedagogical field. Pedagogical press. Programs reform.

\footnotetext{
${ }^{1}$ Faculdad Filosofia y Letras (UBA-FFYL-IICE). CABA, Argentina.
} 
Resumen: A través de la revista La Obra, se analiza la reforma de programas escolares del nivel primario en Argentina en el año 1936, como forma de conocer las discusiones en el campo pedagógico y el rol que jugaron las ideas de la Escuela Nueva. La Obra comenzó a publicarse en el año 1921, y se convirtió en el órgano de difusión de una parte del movimiento escolanovista, hecho que posibilitó la conformación de un espacio de sociabilidad pedagógica a partir del cual sostuvieron posiciones propias, que en algunos casos se opusieron a las políticas educativas oficiales. Como argumento principal, se sostiene que este grupo escolanovista, al incrementar su poder e influencia, motorizó el proceso de reforma que concluyó en 1936 con la sanción de los nuevos programas, en reemplazo de los anteriores, del año 1910.

Palabras clave: Escuela Nueva. Campo pedagógico. Prensa pedagógica. Reforma de programas.

\section{INTRODUCCIÓN}

Una de las principales vías de difusión de la Escuela Nueva en Argentina fue una revista sobre educación desarrollada por maestros, profesores y pedagogos insertos en el sistema oficial de educación pública. Creada en 1921, La Obra se adscribió a la Liga Internacional para la Educación Nueva, siendo la representación, a nivel local, de este movimiento internacional.

El grupo editorial que impulsaba la revista, fue un activo partícipe en las discusiones sobre la realidad educativa nacional, ocupándose de discutir las propuestas que surgían del gobierno del sistema y de proponer proyectos alternativos. Uno de los aspectos por los que se interesó fuertemente la revista, fue el de los programas escolares. Sobre este punto se concentraron las discusiones en los primeros años de la década del 30, hasta lograr la reforma de los mismos en el año 1936.

A partir del análisis de ese proceso, en este artículo se espera generar un aporte a las miradas sobre el campo pedagógico en Argentina, el lugar que ocuparon revistas pedagógicas como La Obra, y la función que cumplieron las ideas de la Escuela Nueva.

\section{LA REVISTA LA OBRA}

La Obra, "revista de educación, ciencias y letras", comenzó a circular en el año 1921. Con regularidad quincenal e impresa en la Capital Federal, tenía llegada al magisterio primario de todo el país. Ya desde su nombre, remite al maestro como un "obrero de nobles designios" 2 con un saber

\footnotetext{
${ }^{2}$ La frase pertenece al himno de la Escuela Normal Mariano Acosta, escrito por el docente de la Escuela Arturo Marasso en 1924.
} 
específico, una técnica. En este sentido, se puede afirmar que la principal función de la revista consistía en acercarle a ese trabajador herramientas para perfeccionar su tarea.

Surgida en un contexto de modernización, La Obra puede pensarse como parte de un universo de revistas culturales y literarias de la cultura argentina de los años veinte y treinta (Sarlo, 1992), modernización cultural que no es ajena a la modernización técnica que permitió imprimir revistas de gran tirada y a precios accesibles para el gran público. Uno de sus principales atractivos era su sección didáctica que brindaba a los maestros una "didáctica práctica desarrollada de acuerdo con métodos activos, simples y rápidos para las escuelas urbanas y rurales" (La Obra, 1921, Tomo I, Pg. 9). Era, en definitiva, una herramienta para que los maestros pudieran perfeccionar su tarea, su obra: "la revista La Obra, con su afán práctico y la preparación del docente para la tarea concreta en el aula se convirtió en la lectura de los docentes asociados a la masificación del sistema educativo [...]" (Finocchio, 2009, p. 129). Pero además de ofrecer herramientas prácticas para el trabajo docente, esta sección estaba precedida por comentarios editoriales en donde la revista sentaba posiciones sobre distintas problemáticas político-pedagógicas. Allí se desarrollaba la línea editorial, se sentaban posiciones y se difundían y defendían iniciativas, como en el caso de las modificaciones de los programas escolares.

La revista no puede explicarse sin el proceso por el cual el Estado argentino asumió el papel de Estado Docente y expandió el sistema escolar público estatal a lo largo y ancho del país, sosteniendo una pedagogía de carácter normalista desarrollada en los núcleos de esa matriz escolar que eran las Escuelas Normales. El compromiso del normalismo con la pedagogía como forma de intervención social está presente en el espíritu fundacional de la revista. Por eso, intentó abstraerse de discusiones que no le eran ajenas, pero que se daban en otros campos: "La Obra es un periódico independiente. No está ligado a partido político alguno. No hace cuestiones políticas ni religiosas." (La Obra, 1921, Tomo I, p. 1). No es ninguna casualidad entonces que La Obra surgiera del seno del Normal Mariano Acosta, uno de los normales históricos ubicado en la Capital del país.

El análisis en términos cuantitativos de la llegada de La Obra al magisterio no carece de dificultad, ya que la propia revista no aporta información editorial que nos permita conocer la cantidad de ejemplares impresos o los lugares exactos del país en los que se leía. Por eso, hay que acudir a otro tipo de datos. Por ejemplo, la información sobre los representantes de la revista en el interior del país ofrece un panorama bastante preciso sobre su circulación nacional. En su primer año de vida, eran 47 representantes distribuidos en 15 territorios nacionales y provincias. Cuatro años después, para el año 1925, 106 hombres y mujeres garantizaban la presencia de la revista en 
20 jurisdicciones de un total de 24 (entre territorios nacionales, provincias, y capital federal). Además, se sabe que era una publicación quincenal que sólo interrumpía su tirada en el mes de enero, por lo que la cantidad de números editados por año superaba los veinte.

A falta de datos exactos sobre La Obra, es útil por lo menos conocer cuál era la magnitud de maestros y maestras en esa época, potenciales consumidores de la revista. Si en el año 1892 había un registro de 7054 maestros, de los cuales sólo 1704 poseían título, esa cifra aumenta exponencialmente para el año 1930, cuando las escuelas normales habían expedido la cantidad de cincuenta mil diplomas entre maestros y profesores (Fiorucci, 2014), que se insertaban en un total de 10063 escuelas primarias estatales, un número realmente grande, incluso comparado con países como México o Estados Unidos. Entre esos docentes formados por el normalismo se encontraba Rosa del Río, la entrañable maestra porteña que Beatriz Sarlo inmortalizó en su trabajo Cabezas rapadas y cintas argentinas. Esta maestra, a partir de un hecho narrado por Sarlo, se convirtió en un exponente de la apropiación del normalismo por parte del magisterio ${ }^{3}$. Pero hay un elemento que señala Sarlo y que no puede ser pasado por alto: Rosa del Río era "lectora convencida de $L a$ Obra [...], tenía la colección completa de la revista" (Sarlo, 1997, p. 198). Las interpretaciones que se desprenden de este hecho pueden ser, por lo menos, dos: o que la revista no tuvo un impacto significativo en las prácticas del magisterio, que consumía la revista pero reproducía prácticas tradicionales; o que la circulación de la revista fue lo suficientemente grande como para alcanzar a maestros que incluso no sintonizaban plenamente con el ideal pedagógico renovador ${ }^{4}$. De cualquier manera, frente a la falta de datos cuantitativos, este relato demuestra la llegada de la revista a una maestra anónima de un barrio popular de la Capital del país, situación que perfectamente se puede hacer extensiva a una parte importante del magisterio.

De hecho, como se señaló más arriba, la propia revista tuvo un origen normalista que no impidió que se convirtiera en la principal herramienta de divulgación de las ideas escolanovistas ${ }^{5}$ en Argentina, incluso con un vínculo formal con la Liga Internacional para la Educación Nueva, asociación internacional fundada en el año 1921. La Liga funcionaba como una red que conectaba

\footnotetext{
${ }^{3}$ Para expresarlo muy sintéticamente, esta maestra normal, en su cargo de directora (que había tomado en 1921) de una escuela de la periferia porteña, decidió convocar a un peluquero, que rapó a una buena parte de los alumnos varones de la escuela frente a una futura posible epidemia de pediculosis, sin solicitar el consentimiento de las familias.

${ }^{4}$ Aunque, para hacer justicia con los maestros como Rosa del Río, es probable que en muchos casos hubiera una práctica híbrida, con elementos tanto tradicionales como renovadores.

${ }^{5}$ En Argentina, la pedagogía que la Escuela Nueva denunciaba como "tradicional", adquiere el nombre de "normalista" por la importancia que tuvieron las Escuelas Normales en la concepción y difusión de las ideas pedagógicas asociadas a la normalización, la disciplina y el positivismo.
} 
revistas pedagógicas alrededor del mundo ${ }^{6}$. La Obra comenzó a ser parte de esa red en el año 1926, cuando anunciaba que si bien desde hacía tiempo se había "incorporado al movimiento de la nueva educación mediante la difusión de sus principios y orientaciones, se adhiere ahora formalmente a la Liga Internacional para la Educación Nueva y a la Oficina Internacional de Educación" (La Obra, 1926, Tomo VI, p. 385).

El trabajo con la prensa pedagógica como fuente aporta elementos fundamentales para comprender tanto los procesos de constitución y desarrollo de los campos pedagógicos, como la circulación del conocimiento pedagógico (Cordeiro y Carvalho, 2005) y las formas de apropiación de ese conocimiento a nivel local ${ }^{7}$. Si se la piensa como dispositivo para el análisis, la revista presenta una variedad de discursos a partir de los cuales se pueden pensar las distintas culturas escolares. Así, la cultura empírica, la cultura académica y la cultura política (Escolano Benito, 2008) están presentes, recogiendo experiencias forjadas en las instituciones escolares; difundiendo el saber experto producido tanto por funcionarios experimentados del sistema como por pedagogos locales o internacionales; o construyendo y disputando normas y leyes para el sistema educativo argentino.

Para analizar el proceso de reforma de los programas escolares, se prioriza aquí un enfoque sobre la dimensión política de la cultura escolar, complementando otras interpretaciones sobre La Obra realizadas en otras investigaciones (Cfr. Finocchio, 2009; Gvirtz, 1996; Narodowski, 1996). Como señala Escolano Benito, "las leyes, los reglamentos y los documentos emanados de las burocracias son textos que expresan su contenido en lenguajes ideológicos y jergas técnicas cuya semántica transmite una determinada cultura." (2008, p. 136). La Obra, además de ser una herramienta didáctica, funcionó como una vía para la difusión de propuestas político-pedagógicas y como un lugar de posicionamiento en la disputa por la imposición de esas propuestas por parte de un grupo de pedagogos -entre los que se encontraba cierta burocracia escolar- que encontró en ella su medio de expresión, especialmente la burocracia integrada por los inspectores escolares.

En relación a la docencia de nivel primario, podemos afirmar que para el año 1921, cuando se fundó la revista, ya se encontraba consolidado el proceso de formación de docentes, necesario para cubrir las demandas del sistema que comenzó a expandirse en la década del 80 del siglo

\footnotetext{
${ }^{6}$ Por caso, para el habla francesa Adolphe Ferrière editaba desde Ginebra (epicentro de la red, allí se encontraba la Oficina Internacional de Educación comandada por el pedagogo suizo) la revista Pour l’Ere Nouvelle.

7 En palabras de Catani y De Souza (2001, p. 243), "es posible partir del estudio de determinados periódicos educacionales y tomarlos como núcleos informativos, en tanto sus características explicitan modos de construir y divulgar discursos legítimos sobre las cuestiones de la enseñanza y sobre el conjunto de prescripciones y recomendaciones sobre formas ideales de realizar el trabajo docente", como en el caso de La Obra.
} 
anterior, por lo cual existía un vasto número de maestros y maestras formados en la horma estatal. La revista estaba destinada a esos docentes, ese era su público: los "queridos camaradas dispersos y semidesterrados" (La Obra, 1921, Tomo I, p. 1) que en la soledad de los territorios profundos encontrarían en La Obra un acompañamiento en la tarea de educar, compañeros "trabajadores del espíritu" alineados bajo la bandera de educar para civilizar. Ese fundamento civilizatorio no se puso en duda. La impronta de la escuela era la impronta de la razón, que llevaba las luces para erradicar la ignorancia. Pero lo que entraría en discusión era el "cómo". Y sobre eso, La Obra ciertamente tenía mucho para decir.

\section{LA REFORMA DE LOS PROGRAMAS DE 1936}

En el ámbito de la Capital Federal regían programas escolares que fueron sancionados en 1910, durante la presidencia del Consejo Nacional de Educación (CNE) de José María Ramos Mejía. La presidencia de este médico psiquiatra constituye un hito en la centralización educativa autoritaria y nacionalista, por lo cual el año de 1910 representa un punto de inflexión en la historia del sistema educativo argentino, que llega en ese momento a mostrar su impronta más contundente en relación con la transmisión de los sentimientos patrióticos. Ramos Mejía ordenó medidas en la línea de la normalización, entre las que estuvo la sanción de nuevos programas escolares para las escuelas de la Capital, tarea que recayó en Ernesto Bavio, Inspector Técnico General de la Capital en esos momentos $^{8}$. Esos nuevos programas debían reemplazar a un proyecto de programas aplicado de manera provisoria, elaborados por Pablo Pizzurno ${ }^{9}$, no casualmente, cuando había sido Inspector Técnico General. Tampoco por casualidad la gestión de Pizzurno terminó con su renuncia, por fuertes diferencias con Ramos Mejía. Ambos tenían puntos de vista incompatibles, especialmente en relación a la cuestión del nacionalismo ${ }^{10}$ (Pineau, 2013, p. 16).

\footnotetext{
${ }^{8}$ Afirma Ramos Mejía en comunicación al CNE: "los programas actualmente en uso en las escuela de la Capital, carecen de vuestra sanción, como que están constituidos por un simple proyecto formulado por el ex Inspector Técnico General, señor Pizzurno, que la anterior presidencia autorizó por vía de ensayo simple" (El Monitor de la Educación Común, 1910, Año XXIX, N. 452, p. 347).

${ }^{9}$ Este pedagogo había tomado posiciones favorables a las tempranas innovaciones que luego se articularían en el movimiento de la Escuela Nueva. Por ejemplo, Pizzurno introdujo el método escandinavo "slöjd" de trabajo manual, rompiendo con la abstracción verbalista del normalismo, lo cual lo ubica en "las posiciones políticas liberales, defensoras del republicanismo, el laicismo y la tolerancia, en una importante articulación con las ideas pedagógicas de la Escuela Nueva" (Pineau, 2013, p. 16).

${ }^{10}$ Para Ramos Mejía, la principal preocupación era "dar a la enseñanza en su espíritu y en su letra, como lo requieren los bien entendidos intereses del país, caracterización fundamentalmente nacional y patriótica, como que la escuela es el molde en que ha de fundirse al futuro ciudadano, a cuya guarda quedarán confiados los destinos de la patria" (EI Monitor de la Educación Común, 1910, Año XXIX, N. 452, p. 348).
} 
La Argentina vivió en la década de 1910 los últimos años del Orden Conservador que se había impuesto en el país desde 1880, y que en términos políticos se caracterizó por una fuerte restricción en la participación de cualquier sector que no fuera parte de la élite política nacional. Ramos Mejía fue un claro representante de ese orden en el CNE, hasta que en 1916 se produjo un cambio rotundo en el rumbo político del país, cuando fue elegido el presidente radical Hipólito Yrigoyen a través del voto popular, lo que implicó un cambio que se materializó desde la primera magistratura hasta instancias como el CNE.

Este proceso de democratización generó un contexto propicio para que algunas tradiciones y jerarquías fueran cuestionadas, y para que sectores como las clases medias encontraran distintas vías de expresión. Este contexto, junto con la creciente difusión de las ideas de la Escuela Nueva a nivel internacional, favoreció que muchos docentes llevaran adelante propuestas pedagógicas renovadoras, y se organizaran en torno a intereses pedagógicos, didácticos y gremiales. El grupo que se nucleó en torno a La Obra presentaba esas características: una organización motivada por intereses pedagógicos y didácticos que también se preocupaba por la cuestión gremial, promotores de las pedagogías renovadoras, y que se sentía en condiciones de proponer modificaciones a las políticas educativas oficiales.

De hecho, desde sus inicios, este grupo había pugnado por modificar los programas escolares de la educación primaria. Es importante remarcar que este núcleo es considerado como el escolanovismo “orgánico" (Puiggrós, 1992), porque sus miembros fueron parte del sistema y de la jerarquía educativa, y por mantener sus propuestas dentro de los parámetros del sistema educativo oficial. En otras palabras, las propuestas eran todo lo disruptivo posible dentro de lo que los marcos legales y normativos lo permitieran. Dentro de esa legalidad, La Obra promovió propuestas de reforma de programas escolares. La primera y más conocida fue la "Reforma Rezzano", implementada en el Distrito Escolar 1ㅇ de la Capital Federal por José Rezzano, Inspector Técnico General de la Capital ${ }^{11}$-director de La Obra y referente de este grupo escolanovista "orgánico"-, reforma de corta duración (entre 1918 y 1924) que perduró hasta que Rezzano se retiró del cargo, enemistado con las autoridades del CNE por diferencias en los criterios político-pedagógicos.

Los programas implementados en el Consejo Escolar 10 fueron sistematizados y publicados por La Obra, que renovaba sus entregas a lo largo de los años. Así llegó al año 1931, cuando un

\footnotetext{
${ }^{11}$ Este era el cargo técnico de mayor jerarquía y responsabilidad de la ciudad. De él dependían los inspectores de cada uno de los distritos porteños (alrededor de veinte para esos años).
} 
nuevo clima autoritario y conservador emanaba desde el poder político nacional, con un golpe de estado en septiembre del año anterior que destituyó al presidente democrático Hipólito Yrigoyen. La avanzada nacionalista y católica que había motorizado el golpe y que se imponía a nivel nacional, desconfiaba de las pedagogías renovadoras, a las que asociaba con la desorganización del sistema que el gobierno militar se proponía a solucionar ${ }^{12}$. Esa desconfianza, sumada al mandato de ordenar una situación "desordenada", desencadenó una disputa por los programas que se implementaban en las escuelas primarias -en muchos casos inspirados o directamente tomados de las propuestas de trabajo de La Obra basadas en la Reforma Rezzano-, los cuales fueron vetados por quien en ese momento fuera el inspector técnico general de la Capital, Valentín Mestroni.

En 1931, Mestroni comunicó unas Instrucciones técnicas para las escuelas de la capital (cuyos destinatarios eran los inspectores de distrito), que fueron publicadas en La Obra, y luego discutidas en sucesivos números. Esas instrucciones especificaban que los programas que debían utilizarse eran solamente los "oficiales". La editorial de la revista lo comunicaba de esta manera:

Transmitiendo las instrucciones del señor Inspector Técnico General, algunos seccionales [Nota: se refiere a los inspectores de distrito] han llegado a afirmar que los Programas de LA OBRA estaban terminantemente prohibidos, y que sólo podían usarse los 'oficiales' insertados en 'el capítulo del Digesto intitulado Programas, (pág. 12 de la edición de 1925)' [...]. Hace ya algunos años, los directores del Consejo Escolar Primero, bajo la dirección del entonces inspector don Juan Vignati, y con la anuencia del doctor José Rezzano, a la sazón Inspector General, resolvieron dar cumplimiento a esa obligación de desarrollar programas y lo hicieron con la participación de vicedirectores y maestros de grado, ajustándose estrictamente al sintético del Digesto y a las disposiciones terminantes de la ley 1420. (La Obra, 1931, Tomo XI, p. 303, destacado de autor).

Como se ve en este fragmento, el grupo escolanovista de La Obra argumentaba que sus acciones se enmarcaban "estrictamente" en los marcos legales del sistema educativo, lo cual no implicaba que dentro de esos marcos, las discusiones fueran en términos muy categóricos cuando había diferencias con la conducción del sistema y con el CNE.

En 1932 se jubiló Valentín Maestroni y fue reemplazado en su cargo de Inspector Técnico de la Capital por Julio Picarel. La Obra reprodujo en la nota Exhortación a los maestros, las primeras palabras dirigidas por el nuevo Inspector hacia el magisterio. En este caso, la revista transmitía el discurso oficial. Se apoyaba a la nueva gestión, lo cual se ve ratificado en la nota siguiente a la del discurso de Picarel, en la que se felicita a la decisión del CNE de ascender a J. Fernando Alvarado al

\footnotetext{
${ }^{12}$ Si bien el tema del posicionamiento del gremio docente y de La Obra excede la temática de este artículo, es preciso señalar que, al igual que una parte importante de la sociedad y del magisterio, la revista manifestó su apoyo al golpe militar que derrocó al gobierno democrático.
} 
cargo de Sub-Inspector General: "Si la jefatura Picarel-Alvarado asignada al cuerpo de inspectores se completa pronto [...] es indudable que la inspección técnica de nuestras escuelas recuperará ipor fin!- la eficiencia de acción y el valor didáctico y moral que hace largo tiempo no tiene" (La Obra, 1932, Tomo XII, p. 331). Aquí, la revista plateaba un apoyo que generaba consenso hacia la conducción del sistema, en una estrategia que se hace palpable más adelante, cuando los redactores de la revista proclamaron la necesidad de reformar "nuestro sistema de enseñanza general y la propia didáctica que le anima y sustenta" (La Obra, 1932, Tomo XII, p. 337). La revista se mostraba convencida de poder fijar, o por lo menos influir, en el rumbo educativo:

Creemos que el momento ha llegado ahora. A ello nos referíamos en parte cuando en los números anteriores expresamos nuestras esperanzas, que mantenemos, acerca de la nueva vida que se abriría para el magisterio argentino y del nuevo derrotero que vislumbrábamos para nuestras escuelas. Hay que dar el envión desde arriba para que tal acontecimiento se produzca, para que esa feliz marcha se emprenda cuanto antes. Con este fin, incitamos al Consejo Nacional de Educación y a la Inspección Técnica General de las escuelas a que den su primer paso en el camino que anhelamos seguir, para lo cual quizá bastase que dispusiesen la realización de una revisión total y a fondo del sistema didáctico imperante, una revisión que debe ser encomendada a una comisión técnica competente y con vistas a una labor sólidamente constructiva. Tal es la gran tarea a realizar que le asignamos a las autoridades superiores de nuestras escuelas primarias. (destacado nuestro) (La Obra, 1932, Tomo XII, p. 338).

En las nuevas disposiciones de la Inspección Técnica General de la Capital, La Obra interpretaba que se "incita e instruye al magisterio de su dependencia para acometer decididamente la acción reformadora del trabajo escolar en modo compatible con los programas vigentes y con los designios de la ley de educación común" (La Obra, 1932, Tomo XII, p. 49, subrayado propio). Las nuevas disposiciones fueron comunicadas por la Primera y la Segunda Circular de la Inspección General, que La Obra transcribe integralmente. En ellas, según la revista,

Se recomienda especialmente a los señores directores, la revisión prolija de los programas analíticos y series graduadas de ejercitaciones a objeto de que guarden la debida correspondencia con la orientación actual de la enseñanza, en el sentido de su aplicabilidad en la vida ordinaria [...] Con respecto a la adopción y aplicación de nuevos sistemas educacionales, los maestros interesados deberán requerir el consentimiento de la Superioridad, previa presentación del plan detallado de trabajos que explique y justifique las ventajas de la iniciativa y los recursos técnicos para su provecho efectivo. (La Obra, 1933, Tomo XIII, p. 93)

Demostrando sus habilidades políticas, la inspección técnica no prohibía las innovaciones que emprendían los docentes, asumiendo que los contenidos debían "corresponderse con la orientación actual de la enseñanza", sino que se propone regularlas, planteando que las innovaciones debían ser "elevadas a la Superioridad" (superioridad es sinónimo de inspección) y 
debidamente justificadas, en un claro intento de incorporar "ordenadamente" las innovaciones pedagógicas. La respuesta de La Obra no se demoró. Si bien para el colectivo

toda la dificultad estriba en convenir qué debemos entender por 'sistema educacional' nuevo [...] los maestros ansiosos de renovación tendrán ahora, con esta segunda circular de la Inspección General, oportunidad para desarrollar en el aula una labor orgánica que satisfaga su justo anhelo (La Obra, 1933, Tomo XIII, p. 94-95).

La revista continuó promoviendo innovaciones en los programas con la difusión de Los programas del Consejo Escolar XX, una nueva propuesta de programas tal como años antes había ocurrido en el Consejo Escolar $1^{\circ}$ :

Ayer fueron los maestros del primero [del C. E. $1^{\circ}$ ] los que encararon la ardua tarea; hoy, doce años después, nos viene un soplo de actividad y de entusiasmo del otro extremo de la gran urbe. [...] Aquel programa, en que alcanzaba su más alto coronamiento el concepto herbartiano entre nosotros, se ve dignamente reemplazado y superado por éste que quiere ajustarse a las nuevas tendencias. (La Obra, 1933, Tomo XIII, p. 297).

Las discusiones se derivaron hacia ámbitos específicos, con la apertura de una Comisión Técnica -integrada por inspectores, directores y vicedirectores- especialmente designada para la sanción de nuevos programas por parte del CNE. La comisión terminó su trabajo en el año 1936, haciendo pública su propuesta, que luego fue aprobada e implementada a nivel nacional como Programa de Asuntos, con vigencia hasta 1961 en la Capital Federal y los Territorios Nacionales ${ }^{13}$ (Palamidessi, 2006, p. 142) ${ }^{14}$.

Había optimismo por parte de La Obra por la reforma, aunque no se abstuvieron de realizar comentarios y críticas. Un claro ejemplo de ese optimismo es la editorial titulada Los nuevos programas para las escuelas comunes de la Capital: cómo se gesta una reforma, en donde plantean que "la reforma que imponen esos nuevos programas en el trabajo de las escuelas ha venido gestándose en la manera que caracteriza a todo movimiento renovador de eficacia incontrastable, esto es, 'de abajo hacia arriba'. Han sido los propios maestros -primero, unos cuantos; luego, a poco andar, muchísimos- quienes comenzaron a realizar esa renovación dentro de su taller particular" (La Obra, 1936, Tomo XVI, p. 89).

\footnotetext{
${ }^{13}$ Es importante destacar que, a diferencia de los programas anteriores, que sólo se aplicaban en la Capital, estos nuevos programas tuvieron un alcance mucho más importante al incluir a las escuelas de los Territorios.

${ }^{14} \mathrm{Si}$ bien, como afirma el autor, no hubo "alteraciones significativas" de los núcleos curriculares fundamentales del sistema escolar, a partir de esos momentos se flexibilizaron el orden disciplinar y los horarios rígidos, con la implementación de los asuntos, inspirados en los centros de interés decrolyanos, en los que la "actividad del niño" prevalecía por sobre las "lecciones" y los "ejercicios" (Palamidessi, 2006: 142).
} 
Es importante remarcar la operación de poner al maestro como sujeto activo de ese proceso, y la idea del "abajo hacia arriba" como forma de presión desde las bases hacia la jerarquía del gobierno escolar. La nota destaca especialmente, en esa genealogía de la reforma, los "ensayos que se hacían en las escuelas, [las] conferencias y los cursos extraoficiales, [la] demanda de informaciones y lecturas técnicas, [el] interés [y las] solicitaciones, en fin, que los docentes dirigían a las autoridades para que se remplazasen los programas vigentes por otros nuevos" (Ibid). Se trataba del triunfo de una prédica de largos años,

tanto en el sentido general de una reforma, cuanto en la manera como habría de concretarse, puesto que los programas aprobados por el CNE, en sus indicaciones didácticas, coinciden en un todo con las aconsejadas desde las columnas de LA OBRA con toda precisión y con todo detalle, de varios años a esta parte (La Obra, 1936, Tomo XVI, p. 49).

Sin embargo, para La Obra, los nuevos programas tenían una gran cantidad de elementos "tradicionales" -por cierto, argumento que utilizaron anteriormente para defender la "legalidad" de las innovaciones, especificando la presencia de elementos tradicionales y afirmando que la renovación no era tan grande como se decía. Por ejemplo, con un "horario exiguo" (escasez de tiempo), además de denunciar una "lujuriosa frondosidad"15. Pero había más críticas: "lo que aprobamos y aplaudimos es el sistema didáctico de los nuevos programas, no el contenido de conocimiento ni de actividades que ellos establecen." (La Obra, 1936, Tomo XVI, p. 49).

La revista interpelaba nuevamente a la comisión, intentando llevar las riendas de la discusión pedagógica, en base a una supuesta "crítica unánime del magisterio", en primer lugar, y luego, como no podía ser de otra manera, la propia. Para La Obra, era necesario poner "las cosas en su lugar":

hay que tener autoridad acreditada y derecho bien ganado para pretender dirigir al magisterio. Es menester haber formado en las filas de sus instituciones representativas, haber corrido los riesgos de las luchas sostenidas por ellas, haber demostrado valor y valía en sus campañas, pasión en sus empresas, capacidad en su existencia; es menester haber vivido activamente la vida de maestro y dado pruebas fehacientes de ilustración y energía durante su transcurso; es menester, en síntesis, haberse sentido siempre maestro y haber estado siempre presente allí donde el magisterio libraba una batalla o empeñaba una acción decisiva en favor de sus miembros o de la escuela. (La Obra, 1936, Tomo XVI, p. 571).

Esta vez, la estrategia volvía a ser confrontativa, muy lejos del apoyo que había dado la revista al recambio de autoridades luego de la jubilación de Mestroni. El grupo escolanovista de La Obra había forzado la implementación de una reforma, logrando que el Estado arbitrara los medios

\footnotetext{
${ }^{15}$ Se refiere a una cantidad excesiva de contenidos. Ya en 1887, otro Inspector Técnico, Juan M. de Vedia, planteaba la necesidad de reformar los planes y programas no sólo para "robustecer la nacionalidad", sino también para liberarlos del "inmenso recargo de asignaturas" (Bertoni, L. (2001) Patriotas, cosmopolitas y nacionalistas. La construcción de la nacionalidad argentina a fines del siglo XIX. Bs. As: FCE.; citado en Teobaldo, 2011.).
} 
(convocar a una comisión específica que tratara el tema) para elaborar nuevos programas. Una vez alcanzado ese objetivo, se volvía a ubicar como un grupo que por fuera de la órbita estatal (aunque sus miembros pertenecieran todos al sistema oficial, La Obra no tenía ningún tipo de dependencia respecto de los poderes estatales) demandaba acciones para implementar en el sistema público. Esto último implicaba además un posicionamiento específico y una búsqueda de legitimidad dentro del campo pedagógico.

Para cerrar este apartado, es interesante destacar una nota del año 1938, dos años después de la reforma A nuevos conceptos, nueva técnica. Como se puede ver, La Obra realiza una operación por la cual se atribuye la reforma de los programas del 36 como una victoria propia:

Hemos tenido la suerte, que no nos envanece pero que sí nos halaga, de hacer triunfar nuestras ideas, las que se abrieron camino y obtuvieron consagración definitiva, no por la única razón de su vigor y su acierto, sino por lo que ellas traducían de la capacidad del magisterio para el pensamiento y la acción. Porque esas ideas hoy triunfantes y consagradas en la vida de nuestras aulas fueron y son las de los maestros que, estudiando y ensayando diariamente, estaban y están todavía creando el sistema educativo que con el andar del tiempo llegará a ser propio y particular de la escuela argentina. (La Obra, 1938, Tomo XVIII, p. 9).

\section{DISPUTAS Y NEGOCIACIONES EN EL CAMPO PEDAGÓGICO}

Para comprender cómo se conjugó un emprendimiento como La Obra con las ideas de la Escuela Nueva en un proceso de disputas dentro del campo pedagógico es ilustrativo poner el foco en la figura del Inspector Técnico General de la Capital, una figura particular dentro de la estructura del sistema, con caracteres propios. Si bien este actor cumplía funciones políticas en tanto coordinación de inspectores seccionales, era un cargo que no tenía una designación política directa, como el presidente del CNE, sino que implicaba una carrera de ascenso a través del escalafón del sistema educativo, en una negociación entre la burocracia escolar y el poder político. La figura del inspector general estaba asociada a los centros de difusión del pensamiento pedagógico, las Escuelas Normales, y en particular las Normales Superiores, en donde se formaban maestros que con el título que otorgaban esas instituciones, tenían habilitada una carrera como docentes de Escuelas Normales y como inspectores.

Autoras como Mirta Teobaldo dan cuenta de una relación compleja de estos funcionarios con la conducción política del sistema, encabezada por el CNE. Como afirma la autora, los inspectores muchas veces implementaron prácticas alternativas a la política oficial, debido "a que en el seno mismo del Consejo, a pesar de la aparente homogeneidad de su política, existieron 
intersticios que posibilitaron la aparición de acciones alternativas y de políticas emergentes" (Teobaldo, 2011, p. 17). Me interesa destacar esto último, la idea de lo alternativo y lo emergente, que la autora ubica en los mismos inicios de la conformación del sistema educativo, en la figura de inspectores como Raúl B. Díaz. Según Teobaldo,

se fue construyendo, desde la génesis misma del campo, un perfil asociado no sólo a la acción burocrática -gestora de la normativa y vigilante de su cumplimiento- sino también un saber técnico provisto por la ciencia pedagógica. En ese sentido, fueron intelectuales y especialistas los que intervinieron en la gestación de la Inspección y, si bien es cierto que la misma ciencia positiva marcó estrictamente los pasos a seguir, fueron ellos quienes [...] se atrevieron a desafiar y revisar las normas, creando otras, acordes a las necesidades del contexto. El proyecto civilizador y modernizador de la escuela nacional dejaba entonces intersticios por donde filtrar acciones alternativas a la política hegemónica, generalmente en manos de estos intelectuales (Teobaldo, 2011, p. 105, destacado nuestro).

También remitiendo al período fundacional, Adriana Puiggrós afirma que en el proceso de constitución del sistema de instrucción pública, centralizado y estatal, y respecto de la "capa dirigente" del CNE (consejeros, inspectores y otros altos funcionarios);

sin llegar a delinear un campo de alternativas antagónicas, existió un espectro de disidencias, donde se fueron generando alianzas y enemistades en ocasiones circunstanciales y en otras definitivas. [...] No hallamos indicios de una expresión grupal orgánica (instituciones, publicaciones, manifiestos u otras) (Puiggrós, 1990, p. 167-168).

El argumento central de este trabajo retoma la idea de los inspectores como agentes intelectuales con cierta autonomía respecto de la conducción política, pero con otras implicancias para el período abordado: en un contexto internacional de circulación de ideas pedagógicas renovadoras, y local, de democratización política, los inspectores, junto a otros agentes como directores escolares y maestros, conformaron un grupo de poder dentro del campo pedagógico que los llevó a disputar políticas educativas tales como la de los programas escolares.

Tanto Puiggrós como Teobaldo dan cuenta de la existencia de "alternativas". Pero es importante remarcar la aclaración de la primera sobre ausencias de "expresiones grupales orgánicas". Si bien hubo expresiones alternativas a la pedagogía hegemónica normalista durante el período fundacional, no lograron constituirse grupalmente. Y en particular, remarcar el hecho de que para Puiggrós, la inexistencia de publicaciones o proyectos editoriales fuera un elemento para fundamentar esa inexistencia grupal orgánica. La revista La Obra y el grupo que la conformó irrumpieron en una etapa en la que el sistema ya estaba consolidado ${ }^{16} \mathrm{y}$, definitivamente, la

\footnotetext{
16 Se puede afirmar que para 1910 había culminado el proceso de consolidación, y el sistema presentaba las características que lo definieron en su máxima expresión: impronta nacionalista, rol principal del Estado nacional y una fuerte centralización.
} 
publicación de esta revista puede considerarse como una expresión grupal orgánica de un sector en particular dentro del campo pedagógico.

Las diferencias se hacen más claras cuando se pone el foco en los inspectores generales que se han mencionado en este trabajo. Haciendo una breve genealogía, según lo que ya se ha planteado, Pablo Pizzurno implementó un proyecto de programas escolares que fue abortado por Ramos Mejía por las diferencias entre ambas personalidades. De alguna manera, podría decirse que Pizzurno, si bien era un referente de peso dentro del mundo de la pedagogía con afinidades hacia las innovaciones pedagógicas, no tenía un grupo que respaldara sus acciones ${ }^{17}$. Él fue reemplazado por Ernesto Bavio, quien se ocupó de cumplir el mandato del presidente del Consejo sin ningún tipo de autonomía ${ }^{18}$, respondiendo al ordenamiento jerárquico del sistema, como lo demuestra la sanción de los programas de 1910.

Con José Rezzano, tenemos otro caso de un Inspector Técnico General de la Capital que desarrolló innovaciones y las aplicó en un distrito escolar durante seis años. Esto le valió una confrontación con las autoridades del CNE, por lo cual terminó renunciando a su cargo, hecho que dejó sin cobertura política a la reforma por él implementada, lo cual hizo que esa experiencia también terminara. Pero a diferencia de Pizzurno, Rezzano había trabajado en la conformación de un espacio de sociabilidad con docentes que compartían un interés por las ideas de la Escuela Nueva, que surgían como una novedad en materia educativa desde Europa y Estados Unidos. Ese espacio de sociabilidad se conformó en torno a una revista, La Obra, a partir de la cual se difundieron los programas alternativos, y se dieron discusiones que terminaron logrando un proceso de reformas de programas a nivel nacional.

El caso de José Mas es otra muestra del funcionamiento de La Obra como un grupo dentro del campo de la pedagogía con inserción en el sistema oficial. Mas era el director de La Obra en el año 1932, cuando obtuvo por concurso un cargo en una de las inspecciones técnicas de la Capital que dependían de la Inspección General. La Obra lo despidió con una afectuosa reseña. El director debía dejar la revista por la incompatibilidad que implicaban ambos cargos (La Obra, 1932, Tomo XII, p. 569). El hecho de que existiera esa incompatibilidad es una muestra clara de que el colectivo

\footnotetext{
17 De hecho, Pizzurno había sido protagonista de un hecho editorial, cuando comenzó a publicar en 1898 la Revista de Instrucción Pública. Silvia Finocchio enfatiza la soledad de este funcionario cuando señala que la revista era su "tribuna personal" (Finocchio, 2009, p. 57).

18 Para González Leandri, en la etapa de fundación del sistema, cuyas características se puede decir que se mantuvieron hasta 1910, la "elite intelectual normalista" (p. 528) no logró dejar de ser una fracción subordinada de la elite intelectual del momento, a la que pertenecía, por ejemplo, Ramos Mejía.
} 
docente asumía muchas veces posiciones de confrontación con la burocracia escolar, pero también debe remarcarse el dato de que La Obra ubicaba a uno de sus cuadros más importantes en un lugar de decisión en ese esquema burocrático, no el de mayor jerarquía, como en el caso de Rezzano, pero ciertamente con posibilidad de influencia en muchas escuelas primarias oficiales.

En síntesis, si se analiza la figura del Inspector Técnico General a la luz de los procesos de disputa por los programas escolares, se puede ver cómo se van fortaleciendo posiciones al interior del campo pedagógico que garantizaban imponer modificaciones y puntos de vista. Mientras que en la disputa Ramos Mejía-Pizzurno había primado la decisión vertical del Consejo, en 1936 se logró imponer una modificación de programas surgida de los reclamos de un sector del cuerpo docente.

\section{REFLEXIONES FINALES}

La Obra fue un emprendimiento editorial con un origen por fuera de las estructuras institucionales, en la esfera de la sociedad civil. Si bien la dimensión de lo estatal es importante para comprender a este emprendimiento (ya se hizo referencia al Estado Docente que formó grandes cantidades de maestros y maestras, quienes serían el público consumidor de la revista, y al hecho de que la revista estaba compuesta en su totalidad por agentes del estado como maestros, directores y supervisores), el último caso reseñado, el de José Mas, es una muestra de los límites que había entre ambas instancias. Una frontera claramente delimitada entre la pertenencia a La Obra y la responsabilidad institucional en el sistema. Ambas eran excluyentes. Al igual que en el caso de José Mas, cuando José Rezzano fue Inspector Técnico General, no tenía responsabilidades formales en la gestión de la revista, dirigida por el maestro Luis Arena. Sin embargo, ambos casos son también muestra de una circulación doble, que sale de las esferas estatales para incorporarse a un emprendimiento editorial no estatal, como en el caso de José Rezzano ${ }^{19}$ y su esposa Clotilde, pero también va en el sentido inverso, desde la revista hacia la gestión oficial, como en el caso de José Mas. Este último caso muestra un aporte de cuadros de la revista a la gestión estatal.

Pero otra forma de influir en las decisiones oficiales por parte de este colectivo editorial, fue a través del planteo de discusiones, como se desarrolló en este artículo, en temas como los programas escolares. Con Roger Chartier, se puede pensar al público docente que consumía la revista como una "comunidad de lectores" (Chartier, 2005, p. X) que construía sus propios sentidos

\footnotetext{
${ }^{19}$ Segú n Silvia Finocchio, Rezzano se incorporó a la redacción de La Obra en 1926, una vez que había renunciado a su cargo de Inspector General (Finocchio, 2009, p. 97).
} 
en base a las lecturas ofrecidas ${ }^{20}$. La Obra era una mediación que llevaba a los docentes las lecturas teóricas de este movimiento pedagógico internacional. Además de los propios sentidos que sobre esas ideas construyeran los docentes en tanto comunidad lectora, la revista intentaba construir sus propios sentidos, expresando sus posiciones en editoriales y notas de opinión que muchas veces cuestionaban las direcciones de la política oficial del CNE. En esa construcción, había una búsqueda de generar consensos con los docentes lectores como forma de dar legitimidad a sus argumentos, logrando un posicionamiento favorable dentro del campo pedagógico, como cuando afirmaban, en relación a la reforma de los programas, que el proceso era "de abajo hacia arriba", interpelando claramente a la base de los docentes. En base a esos consensos, La Obra se consideraba la legítima representación del colectivo docente, como cuando afirmaba que había una "crítica unánime" por parte de los docentes hacia los nuevos programas. Por todo esto, también puede pensarse a La Obra, con Viñao ${ }^{21}$, como elemento “aglutinante" (Viñao, 1994-1995, p. 10) de una porción de la docencia argentina favorable las ideas pedagógicas renovadoras.

En este sentido, sería un error considerar a la reforma del 36 como una acción directamente emprendida por la revista. Lo que interesa remarcar es no solamente el rol que tuvo la revista como difusora de ideas, sino también como productora de las mismas. La Obra promovió una experimentación pedagógica en las escuelas que preparó el campo para que luego esos cambios se institucionalizaran a nivel legal, legalizando un hecho que se venía produciendo.

Además, el carácter novedoso de las ideas de la Escuela Nueva permite introducir la variable del capital simbólico. En este sentido, los maestros y pedagogos del colectivo editorial disputaron posiciones de legitimidad en el campo pedagógico argentino, confrontando con lo que ellos consideraban una "pedagogía tradicional" desde las críticas que realizaba el movimiento renovador.

Si las ideas de la Escuela Nueva se posicionaban como lo innovador, el grupo de La Obra detentaba la legitimidad de esa innovación, buscando imponer sus posiciones sobre otros actores asociados a lo tradicional. Según Bourdieu, "la estructura del campo es un estado de la relación de fuerzas entre los agentes y las instituciones que intervienen en la lucha" (Bourdieu, 2003, p. 90). En este caso tenemos una situación en la que agentes e instituciones generaron consensos en el colectivo docente nacional mejorando su posición en la relación de fuerzas, y se convirtieron en los

\footnotetext{
${ }^{20}$ Este elemento, que queda planteado como hipótesis, debería ser considerado en las investigaciones que aborden el tema de la recepción y apropiación de la Escuela Nueva en Argentina.

${ }^{21}$ Antonio Viñao propone esta idea al analizar la Revista de Pedagogía, que en España cumplió un rol similar al de La Obra en Argentina.
} 
transmisores "legítimos" de un discurso pedagógico (la Escuela Nueva). De esta manera, consenso y capital simbólico fueron dos de las formas, entonces, por las que este grupo disputó posiciones de poder en el campo pedagógico, en una disputa entre los "tradicionales" y los "renovadores". En esa disputa, las ideas de la Escuela Nueva tuvieron un rol primordial, al igual que La Obra, el medio a través del cual fueron difundidas.

\section{REFERENCIAS}

\section{Fuentes primarias}

Revista La Obra, Tomos I, VI, XI, XII, XIII, XVI, XVIII.

Revista El Monitor de la Educación Común, N. 452.

\section{Bibliografía}

Bourdieu, Pierre. Campo de poder, campo intelectual. Buenos Aires: Quadrata, 2003.

Catani, Denice; De Souza, Cynthia. A geração de instrumentos de pesquisa em História da Educação: estudo sobre revistas de ensino. Em Gonçalves Vidal, Diana; Hilsdorf, Maria Lúcia (Org.) Brasil 500 anos. Tópicas em História da Educação. São Paulo: EDUSP, 2001.

Chartier, Roger. El mundo como representación. Estudios sobre historia cultural. Barcelona: Gedisa, 2005.

Cordeiro, Jaime; Carvalho, Luís Miguel. Educational Journals and Worldwide Circulation of Pedagogical Knowledge: Brazil and Portugal (1921-1935). Paedagogica Historica, v. 41, n. 1-2, p. 131-141, 2005.

Escolano Benito, Agustín. La escuela como construcción cultural. El giro etnográfico en la historiografía de la escuela. Espacios en Blanco. Revista de Educación, Buenos Aires, v. 18, p. $131-$ 146, 2008. Disponible en: http://www.redalyc.org/articulo.oa?id=384539800006. Consultado en: 20 de febrero de 2020.

Finocchio, Silvia. La escuela en la historia argentina. Buenos Aires: Edhasa, 2009.

Fiorucci, Flavia. Maestros para el sistema de educación pública. La fundación de escuelas normales en Argentina (1890-1930). En Revista Mexicana de Historia de la Educación, v. I, n. 3, p. 25-45, 2014.

González Leandri, Ricardo. La elite profesional docente como fracción intelectual subordinada en Argentina: 1852-1900. Anuario de Estudios Americanos, t. LVII, n. 2, pp. 513-535, 2001.

Gvirtz, Silvina. La estrategia de la Escuela Nueva a través de la revista "La Obra" y sus propuestas didácticas. En Gvirtz, Silvina (Comp.). Escuela Nueva en Argentina y Brasil. Visiones comparadas. Buenos Aires: Miño y Dávila, 1996.

Gvirtz, Silvina. El discurso escolar a través de los cuadernos de clase. Argentina (1930 y 1970 ). Buenos Aires: Eudeba-FFYL-UBA, 1999. 
Narodowski, Mariano. Silencios y márgenes. La Escuela Nueva en la historiografía educacional argentina. En Gvirtz, Silvina (Comp.). Escuela Nueva en Argentina y Brasil. Visiones comparadas. Buenos Aires: Miño y Dávila, 1996.

Palamidessi, Mariano. El currículum para la escuela primaria argentina: continuidades y cambios a lo largo de un siglo. En Terigi, Flavia (Comp.). Diez miradas sobre la escuela primaria. Buenos Aires: Siglo XXI, 2006.

Pineau, Pablo. Presentación. En Pizzurno, Pablo. Cómo se forma al ciudadano y otros escritos reunidos. Buenos Aires: Unipe, 2013.

Puiggrós, Adriana. Sujetos, disciplina y currículum en los orígenes del sistema educativo argentino. Buenos Aires: Galerna, 1990.

Puiggrós, Adriana. La educación argentina. Desde la Reforma Saavedra Lamas hasta el fin de la Década Infame en Puiggrós (Dir.). Historia de la Educación Argentina, Tomo III: Escuela, Democracia y Orden (1916-1943). Bs. As: Galerna, 1992.

Sarlo, Beatriz. La imaginación técnica: sueños modernos de la cultura argentina. Buenos Aires: Nueva Visión, 1992.

Sarlo, Beatriz. Debate sobre la ponencia de Beatriz Sarlo. En Prismas. Revista de historia intelectual, año 1, n. 1, pp. 196-200, 1997.

Teobaldo, Mirta. Buenos días, Sr. Inspector!: historia de los inspectores escolares en la Patagonia Norte: Río Negro y Neuquén. Perfil y funciones (1884-1962). Córdoba: Universidad Nacional de Córdoba, 2011.

Viñao, Antonio. La modernización pedagógica española a través de la "Revista de Pedagogía" (1992-1936), Anales de Pedagogía, n. 12-13, pp. 7-45, 1994-1995.

\section{SOBRE EL AUTOR}

\section{Ignacio Frechtel}

Doctorando en Ciencias de la Educación, UBA-FFYL-IICE. Becario doctoral por la misma institución. CABA, Argentina.

E-mail: ignaciofrechtel@gmail.com.

ORCID: https://orcid.org/0000-0002-3957-3004

Recibido: $10 / 03 / 2020$

Aprobado: $01 / 04 / 2020$

Publicado: 07/04/2020 